\title{
Gynaecomastia in 786 adult men: clinical and biochemical findings
}

\author{
Mikkel G Mieritz, Peter Christiansen, Martin Blomberg Jensen, Ulla N Joensen, \\ Loa Nordkap, Inge A Olesen, A Kirstine Bang, Anders Juul and Niels Jørgensen \\ Department of Growth and Reproduction, Rigshospitalet, University of Copenhagen, \\ Copenhagen, Denmark
}

Correspondence should be addressed to M G Mieritz Email

m.mieritz@gmail.com

\begin{abstract}
Objective: Gynaecomastia is a benign proliferation of glandular tissue of the breast; however, it is an important clinical observation because it can be the first symptom of an underlying disease. Some controversy exists concerning the clinical importance of an in-depth investigation of men who develop gynaecomastia. We hypothesise that a thorough work-up is required in adult men with gynaecomastia.

Design: All adult men $(n=818)$ referred to a secondary level andrological department at Rigshospitalet in Copenhagen, Denmark during a four-year period (2008-2011) under the diagnosis of gynaecomastia (ICD-10: N62) were included.

Methods: Thirty-two men who did not have gynaecomastia when examined were excluded; leaving 786 men for final analyses. They underwent an andrological examination, ultrasound of the testicles and analysis of endogenous serum hormones levels.

Results: In $43 \%$ of men with adult onset of gynaecomastia ( $\geq 18$ years) an underlying, and often treatable, cause could be detected. In men younger at onset an underlying cause for gynaecomastia could be detected in merely $7.7 \%$. The study is limited by the fact that we did not have access to investigate men who were referred directly by their GP to private clinics for plastic surgery or who sought cosmetic correction without consulting their GP first.

Conclusions: Our study demonstrates the importance of a thorough examination and provides a comprehensible examination strategy to disclose the underlying pathology leading to the development of gynaecomastia
\end{abstract} in adulthood.

\section{Introduction}

Breast development, gynaecomastia, in boys and men is a common condition (1). It is a benign proliferation of glandular tissue of the breast (2); however, it is an important clinical observation because it can be the first symptom of an underlying disease. Some controversy exists concerning the clinical importance of an in-depth investigation of adult men who develop gynaecomastia, but this study combined with earlier reports provides evidence for a comprehensive approach $(3,4,5)$.
(C) 2017 European Society of Endocrinology Printed in Great Britain
European Journal of Endocrinology

(2017) 176, 555-566 
of gynaecomastia, but often no underlying aetiology can be identified. Gynaecomastia has been reported to be 'idiopathic' in $61 \%$ of cases (13), leaving clinicians with few options to identify causal and/or treatable factors for most men. This is often the main argument for omitting a thorough work-up of men with palpable benign breast enlargement, but large retrospective and consecutive studies are lacking. We evaluated clinical and biochemical findings from a detailed suitable primary diagnostic work-up in a large consecutive cohort of adult men referred to our andrology outpatient clinic under the diagnosis of 'Gynaecomastia' (ICD-10: N62) during a fouryear period (2008-2011).

\section{Subjects and methods}

\section{Participants and clinical examination}

All men (age $\geq 18$ years) referred for evaluation of unilateral or bilateral gynaecomastia (ICD-10: N62) from 2008 to 2011, who underwent a structured work-up with clinical examination and blood sampling at the Department of Growth and Reproduction at Rigshospitalet, were included. In total 818 men were examined, however, the clinical examination showed that 32 men actually did not have gynaecomastia, thus leaving 786 patients for final analysis. If referrals included information on current or recent $(<2$ years) abuse of anabolic steroids (AAS), the men were not evaluated.

A detailed medical history was obtained, including information on self-reported onset of gynaecomastia - no preselection or differentiation between different symptoms of gynaecomastia at onset, e.g. soreness, protrusion of the nipple, was made. Gynaecomastia was defined as the presence of palpable glandular tissue. The physical examination included the evaluation of the presence of gynaecomastia (unilateral and/or bilateral) by palpation and determination of size of glandular tissue (largest diameter). The recording of unilateral or bilateral gynaecomastia was not specified for 265 men. Testis size was determined by palpation using an orchidometer, and testicular ultrasound examination was performed for volume measurement and to identify testicular tumours (14). All examinations were performed by trained andrologists.

Body height was measured using a calibrated wallmounted Harpenden stadiometer (Holtain Ltc, Crymych, United Kingdom) and weight using a calibrated electronic scale (Bisco model PERS 200, Farum, Denmark) wearing light clothing.

\section{Blood sampling}

All men had blood samples taken and analysed for reproductive hormones, prolactin, thyroid hormones, liver enzymes, creatinine, sodium, potassium, human chorionic gonadotropin (hCG) and alpha foeto protein. If results were outside the reference levels, new blood samples were taken for repeated analysis of the variables.

\section{Serum hormone analyses}

Serum concentrations of follicle-stimulating hormone (FSH), luteinising hormone (LH) and sex hormonebinding globulin (SHBG) were measured by TR-IFMAs (Delfia, Perkin Elmer). Detection limits (LODs) and inter- and intra-assay coefficients of variation (CVs) were $0.05 \mathrm{IU} / \mathrm{L}, 2.7$ and $2.1 \%$ for $\mathrm{FSH}, 0.05 \mathrm{IU} / \mathrm{L}, 1.94$ and $3.0 \%$ for $\mathrm{LH}$ and $0.23 \mathrm{nmol} / \mathrm{L}, 7.51$ and $5.1 \%$ for SHBG. Serum total testosterone (tT) was measured by radioimmunoassay using DPC Coat-A-Count RIA kits obtained from Diagnostic Products Corp. (Los Angeles, California, USA), with LOD $0.23 \mathrm{nmol} / \mathrm{L}$ and inter- and intra-assay CVs of 12.8 and $17 \%$. The assay was compared against LC-MS/MS methodology with excellent performance at levels above $5 \mathrm{nmol} / \mathrm{L}$ (15). Estradiol (E2) was measured by radioimmunoassay (Pantex, Copenhagen, Denmark) with LOD of $18 \mathrm{pmol} / \mathrm{L}$, inter-CV of 14.9 and intra-CV of 7.5. Until 2010, serum inhibin B was measured using double antibody enzyme immunometric assays (Oxford Bio-Innovation) with a LOD of $20 \mathrm{pg} / \mathrm{mL}$ and intra- and inter-assay CVs $<16 \%$. From 2010, inhibin B was measured using the Beckman Coulter Inhibin B genII assay, with a LOD of $3 \mathrm{pg} / \mathrm{mL}$ and intra- and inter-assay CVs $<11 \%$. The two methods were compared and agreement was observed. Free testosterone (cFT) (Vermeulen, Verdonck et al. 1999) and free estradiol (cFE2) were calculated (16), taking SHBG into account and assuming a fixed albumin at $43.8 \mathrm{~g} / \mathrm{L}$. Age-related reference ranges for these assays are based on healthy Danish men as previously published $(17,18,19,20)$.

Prolactin was measured on BRAHMS Kryptor (BRAHMS GmbH, Hennigsdorf, Germany) (LOD $25 \mathrm{mIU} / \mathrm{L}$, with a day-to-day precision of 5-8\%). Thyroidstimulating hormone (LOD $0.014 \mathrm{mIU} / \mathrm{L}$, day-to-day precision of $4-6 \%$ ), thyroxine (T4) (LOD $5.4 \mathrm{nmol} / \mathrm{L}$, dayto-day precision of $7 \%$ ) and free $\mathrm{T} 4$ (LOD $0.3 \mathrm{pmol} / \mathrm{L}$, day-to-day precision of 7\%) were analysed on a Modular ANALYTIC-SP/ISE-E-module system (Roche Diagnostics), using the CFAS-specific Roche calibrators and the Roche Modular reagents for all assays. 


\section{Classification of causes of gynaecomastia}

The diagnosis of an underlying Leydig cell insufficiency was based on the evaluation of testosterone and LH measurement and by the bivariate testosterone-LH plot (21). This setup also enables us to classify the men in primary, secondary or mixed deficiency. If the reason for testosterone deficiency was unclear, hCG, GnRH and/or Clomiphene tests were performed to support the diagnosis. If the response was insufficient on both pituitary/hypothalamic and gonadal levels, the testosterone deficiency was categorised as 'mixed'.

Diagnosed underlying causes were grouped into sexchromosomal and genetic disorder (Klinefelter syndrome, Kennedy syndrome or 47 and XYY), tumours (breast cancer, Leydig cell tumours, Sertoli cell tumours or germ cell tumours), other endocrine disorders (Cushing's disease, hyperthyroidism, hyperprolactinaemia), liver insufficiency, medication due to comorbidities, AAS or cannabis, persistent pubertal gynaecomastia and 'unexplained' gynaecomastia. If more than one contributing factor was discovered, the treatable cause if existing was set as the main underlying cause.

\section{Statistical analyses}

Descriptive variables are displayed as medians and ranges (min-max). For men reporting that gynaecomastia had persisted since puberty, but who could not recall the exact age at onset, it was arbitrarily set to 16 years of age in the analyses. Comparisons of hormone levels between causal groups (with $n \geq 5$ ) were performed on nontransformed data using the Mann-Whitney test using the 'unexplained' subgroup as the reference. Controlling for age was performed on selected groups and variables by logistic regression if median age was significantly different from the 'unexplained' subgroup. $P$ values $\leq 0.05$ were considered significant.

The diagnosis of an underlying pathology based on blood samples were only accepted if the pathological finding of the first blood sampling was confirmed by analysis of the second. However, as it was only a subset of analyses that were repeated, the primary blood samples were used for description in 'Results' section.

\section{Ethical considerations}

Ethical approval was not required as the analyses of patient records did not involve renewed contact with patients. The study was registered with and approved by the Danish Data Protection Agency (j.nr. 2012-41-0797).

\section{Results}

All underlying conditions were undiagnosed until referral for gynaecomastia and were identified due to the specific investigations.

Median age at examination was 35 years (18-91 years (median (range)) of the total 786 included men. Duration of gynaecomastia was 1.2 years (0.1-45.6), and age at onset was younger than 18 years in 196 (25\%) of the men. In men with pubertal onset, the median size of glandular tissue was $4 \mathrm{~cm}(1-10)$, and $3 \mathrm{~cm} \mathrm{(1-10)} \mathrm{in} \mathrm{men} \mathrm{with} \mathrm{adult}$ onset. Gynaecomastia was bilateral in 269 of 521 (52\%) men, and unilateral in 252/521 (48\%), left-sided in 141 and right-sided in 111.

\section{Pubertal onset gynaecomastia ( $<18$ years, $n=196(25 \%))$}

In men with onset of gynaecomastia younger than 18 years, the median age at onset was 14 years $(8-18)$ and the duration at the time of examination was 10.2 years (0.41-45.6). In 7\% (14/196) of the men an underlying cause of gynaecomastia could be identified. One was diagnosed with XYY Syndrome (karyotype 47, XYY), when he was referred for investigation of gynaecomastia at the age of 16 years; one had smoked cannabis at the time gynaecomastia developed; 12 (6\%) had a current or recent use of anabolic steroids, but the majority 182 (93\%) were without any detectable underlying condition despite the extensive investigation and thus classified as having 'persistent pubertal gynaecomastia'.

\section{Adult onset gynaecomastia ( $>18$ years, $n=590(75 \%)$ )}

Table 1 summarises the main underlying causes of gynaecomastia and the anthropometric characteristics of the adult patients.

Age at onset of gynaecomastia was 42 years (18-91) in the group of men with adult onset of gynaecomastia and the duration at the time of examination was 0.6 years (range 0.1-36.7). Misuse of anabolic steroids $(n=76)$ or cannabis $(n=3)$ was reported in 79 men and considered as the basic cause for their development of gynaecomastia. In the remaining 511 men, testicular problems were the main cause for gynaecomastia in 91 men (17.8\%); some degree of testosterone 


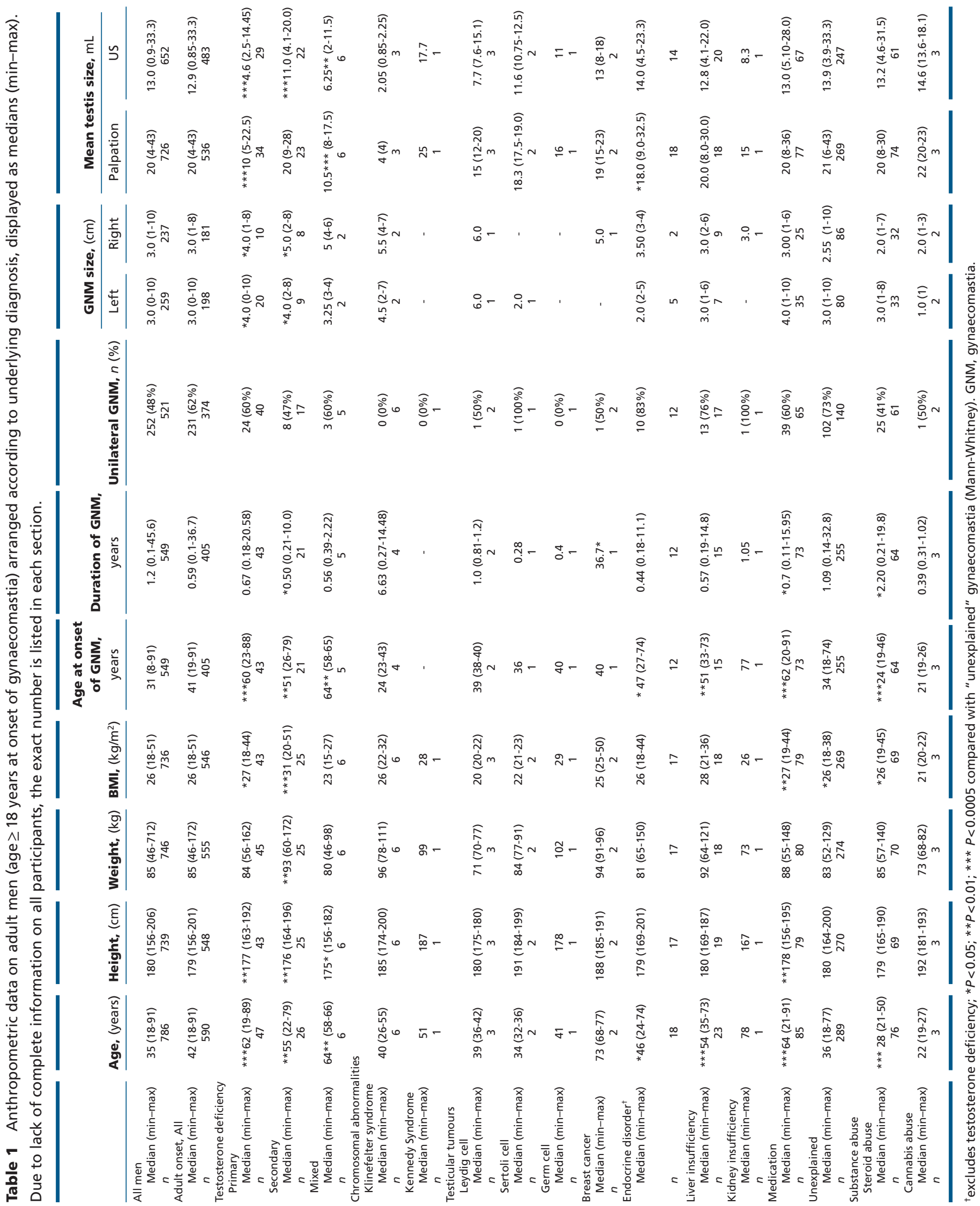




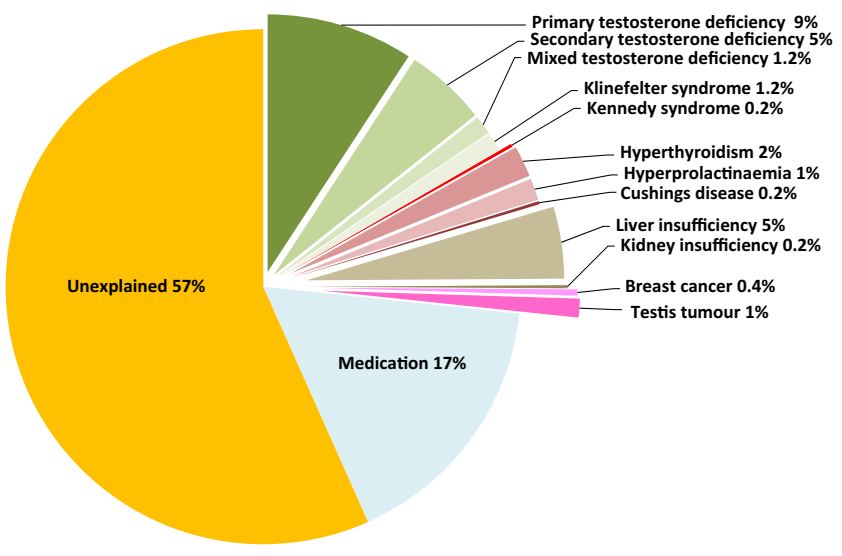

Figure 1

Pie chart showing the distribution of underlying causes of gynaecomastia with adult debut in men with no substance abuse.

deficiency was detected in 79 men (15.4\%), 6 men were diagnosed with Klinefelter syndrome (1.2\%) and 6 with testicular tumours (1.2\%). Concomitant or recent use of medication known to be associated with the development of gynaecomastia for various comorbidities was the second most frequent cause ( $n=85,16.6 \%)$, whereas the other reasons highlighted in Table 1 were all less frequent.

Among the 511 men, the reason remained 'unexplained' in 289 (57\%). The palpable gynaecomastia in these men were additionally confirmed by ultrasound examination in 65 (23\%) of these. Figure 1 summarises the distribution of causes of adult onset gynaecomastia excluding men who used anabolic steroids or cannabis.

\section{Testosterone deficiency}

Men with testosterone deficiency had smaller testicles than the 'unexplained' group $(P<0.01)$, assessed by palpation and US (Table 1). Testis size was the smallest in men with primary testosterone deficiency. Men with testosterone deficiency were shorter than men in the unexplained group. However, for those with primary and secondary testosterone deficiency, the difference was no longer significant when controlled for age or BMI in a logistic regression model. Patients with primary and mixed testosterone deficiency, including Klinefelter patients, had elevated gonadotrophins and SHBG, reduced levels of tT, cFT and inhibin B (Table 2). Furthermore, in these men, tT/LH, cFT/LH and inhibin B/FSH were reduced, whereas cFE2/cFT was elevated (Table 3).
Figure 2 illustrates testosterone and LH levels as well as hormone ratios depicted on a reference curve. Some men with clinical signs of testosterone deficiency had serum levels of $\mathrm{tT}$ that were within the normal reference level, although in the lower range. However, these men were characterised by an abnormal tT/LH and/or cFT/LH ratio; this mismatch is clearly seen in Fig. $2 \mathrm{D}$ and $\mathrm{E}$. In two individuals only one of these ratios were abnormal (one with high E2/tT and cFE2/cFT and one with empty sella but no available ratios due to lack of SHBG).

\section{Testicular tumours}

The ultrasound examinations showed testicular tumours in six men, and none of these tumours were detected by palpation alone. Two men with Sertoli cell, three men with Leydig cell tumours, and one man with a germ cell tumour. Patients with Leydig cell tumours tended to have lower levels of FSH and elevated E2, cFE2, E2/tT and cFE2/cFT compared to controls, whereas reproductive hormones did not differ in men with Sertoli cell tumours compared to controls; however, the levels of FSH and LH tended to be higher and $\mathrm{tT} / \mathrm{LH}$ and $\mathrm{cFT} / \mathrm{LH}$ ratios tended to be lower. Only one man was diagnosed with a malignant germ cell tumour (seminoma), and he presented with low gonadotrophins, high E2/tT ratio and cFE2/cFT, but did not have detectable elevation of hCG.

\section{Medication-induced gynaecomastia}

Use of medication was mainly reported in older men (64 years (21-91 years), $n=85$ ) suffering from comorbidities and use of drugs is known to be associated with gynaecomastia. Table 4 summarises the medications taken by the men in this group. These 85 men had lower levels of tT $(P=0.018)$ and cFT $(P<0.0005)$ and elevated FSH $(P<0.0005)$, LH $(P<0.0005)$, E2 $(P=0.036)$, SHBG $(P<0.0005)$ and inhibin B $(P=0.014)$ compared with the 'unexplained'. However, when adjusted for age in a logistic regression model, only the difference in LH, SHBG, tT/LH and cFT remained significant.

\section{Other causes}

In 23 men (median age 45 years (35-73)), the biochemical evaluation revealed parenchymal liver problems (elevated alanine transferase and lactate dehydrogenase) as the only discernible explanation 


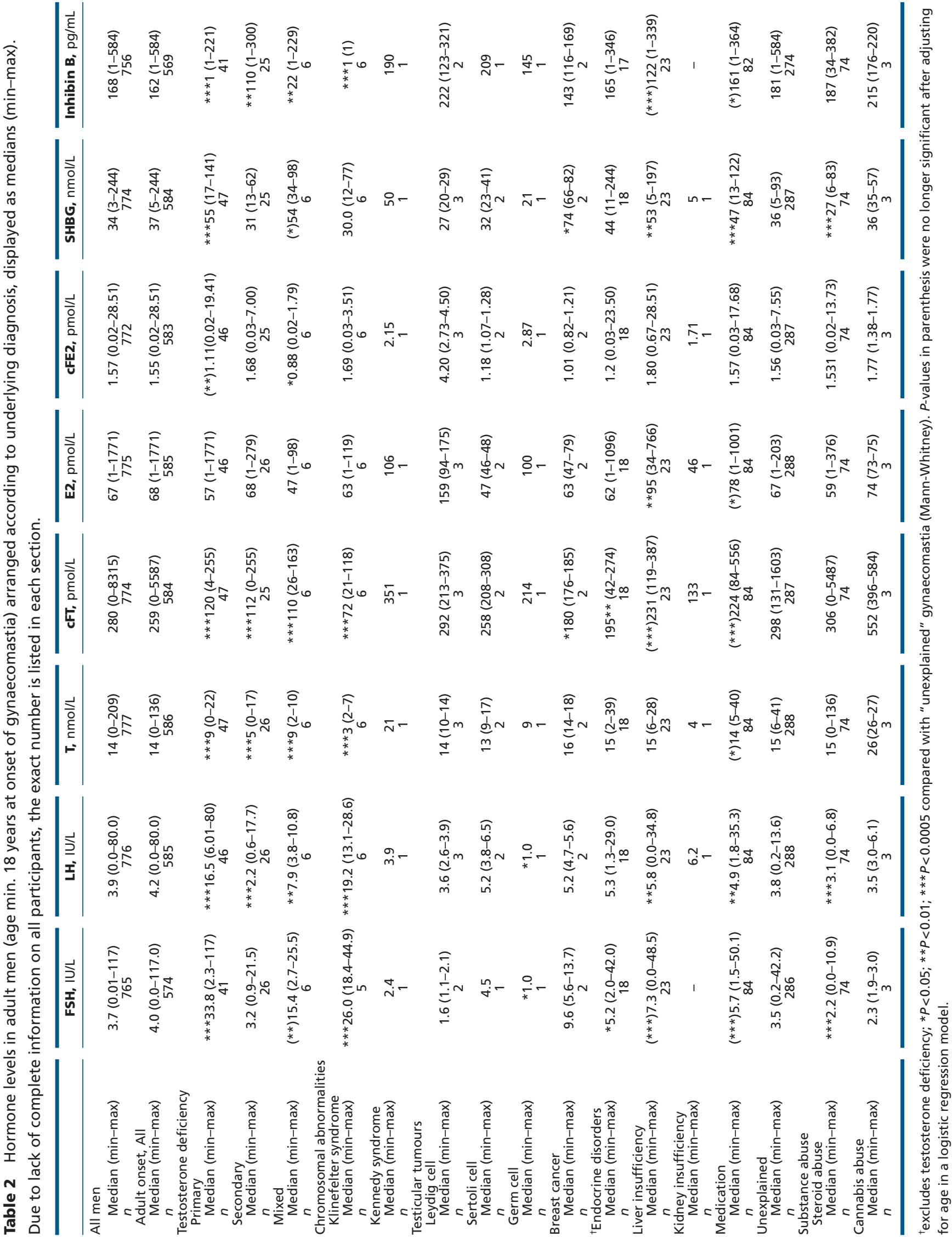


Table 3 Hormone ratios in adult men (age min 18 years at onset of gynaecomastia) arranged according to underlying diagnosis, displayed as medians (min-max). Due to lack of complete information on all participants, the exact number is listed in each section.

\begin{tabular}{|c|c|c|c|c|c|}
\hline & E2/T, pmol/nmol & $100 * \mathrm{CFE} 2 / \mathrm{cFT}$ & $\begin{array}{c}\text { Inhibin B/FSH, } \\
\mathrm{pg} / \mathrm{mL} / \mathrm{IU} / \mathrm{L}\end{array}$ & tT/LH, nmol/lu & cFT/LH, pmol//U \\
\hline \multicolumn{6}{|l|}{ All } \\
\hline Median (min - max) & $4.6(0.1-8500)$ & $0.60(0.0-967)$ & $48.02(0.01-18800)$ & $3.8(0.0-20854)$ & $74(0-821582)$ \\
\hline$n$ & 774 & 772 & 754 & 775 & 773 \\
\hline \multicolumn{6}{|l|}{ Adult onset, All } \\
\hline Median $(\min -\max )$ & $4.7(0.1-8500)$ & $0.60(0.0-967)$ & $43.28(0.01-16300)$ & $3.5(0.0-13601)$ & $66(0-548681)$ \\
\hline$n$ & 585 & 583 & 567 & 585 & 583 \\
\hline \multicolumn{6}{|l|}{ Testosterone deficiency } \\
\hline \multicolumn{6}{|l|}{ Primary } \\
\hline Median (min - max) & $* * * 8.7(0.2-131)$ & $* * * 1.20(0.0-19.8)$ & ***0.05 (0.01-29.88) & $* * * 0.5(0.0-1.8)$ & $* * * 7(0-23)$ \\
\hline$n$ & 46 & 46 & 40 & 46 & 46 \\
\hline \multicolumn{6}{|l|}{ Secondary } \\
\hline Median (min - max) & $* * * 10.8(0.6-2500)$ & ***1.39 (0.1-372.5) & $44.75(0.12-305)$ & $* * * 2.29(0.0-7.9)$ & ***40 (0-143) \\
\hline$n$ & 26 & 25 & 25 & 26 & 25 \\
\hline \multicolumn{6}{|l|}{ Mixed } \\
\hline Median (min - max) & $5.2(0.5-9.7)$ & $0.80(0.1-1.38)$ & $1.23(* *)(0.05-83.88)$ & $* * * 1.0(0.3-2.4)$ & ***14 $(4-42)$ \\
\hline$n$ & 6 & 6 & 6 & 6 & 6 \\
\hline \multicolumn{6}{|c|}{ Chromosomal abnormalities } \\
\hline \multicolumn{6}{|l|}{ Klinefelter syndrome } \\
\hline Median (min - max) & $26.5 * *(0.2-56.1)$ & $3.37 * *(0.00-8.60)$ & $* * * 0.04(0.02-0.05)$ & $* * * 0.2(0.1-0.3)$ & $* * * 4(1-6)$ \\
\hline$n$ & 6 & 6 & 5 & 6 & 6 \\
\hline \multicolumn{6}{|l|}{ Kennedy syndrome } \\
\hline Median (min - max) & 5.0 & 0.60 & 80.50 & 5.5 & 90 \\
\hline$n$ & 1 & 1 & 1 & 1 & 1 \\
\hline \multicolumn{6}{|l|}{ Testicular tumours } \\
\hline \multicolumn{6}{|l|}{ Leydig cell } \\
\hline Median (min - max) & $12.9(6.5-16.2)$ & $1.54(0.70-2.00)$ & $175.6(59.4-291.8)$ & $3.8(3.5-4.1)$ & $82(76-106)$ \\
\hline$n$ & 3 & 3 & 2 & 3 & 3 \\
\hline \multicolumn{6}{|l|}{ Sertoli cell } \\
\hline Median (min - max) & $4.0(2.8-5.2)$ & $0.50(0.40-0.60)$ & 46.55 & $2.9(1.38-4.42)$ & $57(32-80)$ \\
\hline$n$ & 2 & 2 & 1 & 2 & 2 \\
\hline \multicolumn{6}{|l|}{ Germ cell } \\
\hline Median (min - max) & 11.4 & 1.34 & $145.0 *$ & 9.1 & 221 \\
\hline the & 1 & 1 & 1 & 1 & 1 \\
\hline \multicolumn{6}{|l|}{ Breast cancer } \\
\hline Median (min - max) & $4.0(3.4-4.6)$ & $0.60(0.50-0.70)$ & $19.40(8.47-30.34)$ & $3.0(3.0-3.1)$ & $35(33-37)$ \\
\hline$n$ & 2 & 2 & 2 & 2 & 2 \\
\hline \multicolumn{6}{|c|}{ Endocrine disorders (excl testosterone deficiency) } \\
\hline Median ( $\min -\max )$ & $4.5(0.5-107.8)$ & $0.60(0.10-14.6)$ & $34.46(0.03-111.7)$ & $(* *) 2.5(0.7-12.0)$ & $* * * 37(5-209)$ \\
\hline$n$ & 18 & 18 & 17 & 18 & 18 \\
\hline \multicolumn{6}{|l|}{ Liver insufficiency } \\
\hline Median (min - max) & (*)6.3 (2.2-74.4) & **0.86 (0.30-7.60) & $(* * *) 16.22(0.02-10400)$ & $(* *) 2.8(0.7-1029)$ & $(* * *) 40(7.06-37415)$ \\
\hline$n$ & 23 & 23 & 23 & 23 & 23 \\
\hline \multicolumn{6}{|l|}{ Kidney insufficiency } \\
\hline Median (min - max) & 12.2 & 1.28 & - & 0.6 & 22 \\
\hline$n$ & 1 & 1 & & 1 & 1 \\
\hline Medication & & & & & \\
\hline Median (min - max) & $(* *) 5.5(0.1-54.9)$ & $(* * *) 0.70(0.00-7.40)$ & $(* * *) 34.16(0.02-161.98)$ & $* * * 2.9(0.5-9.6)$ & $* * * 50(5-218)$ \\
\hline$n$ & 84 & 84 & 82 & 84 & 84 \\
\hline Unexplained & & & & & \\
\hline Median (min - max) & $4.3(0.1-17.6)$ & $0.50(0.00-2.20)$ & $51.47(0.02-676.5)$ & $4.0(0.9-206.7)$ & 79 (12.12-8017) \\
\hline$n$ & 288 & 287 & 284 & 288 & 287 \\
\hline Substance abuse & & & & & \\
\hline Steroid abuse & & & & & \\
\hline Median (min - max) & $4.50(0.3-8500)$ & $0.50(0.00-967)$ & ***89.03 (5.32-16300) & $\left.{ }^{*}\right) 4.6(1.0-13601)$ & $(* *) 99(22.30-548681)$ \\
\hline$n$ & 74 & 74 & 74 & 74 & 74 \\
\hline Cannabis abuse & & & & & \\
\hline Median (min - max) & $2.9(2.9-2.9)$ & $0.30(0.30-0.40)$ & $97.35(58.7-116.2)$ & $7.4(4.2-8.8)$ & $157(65.4-192.0)$ \\
\hline$n$ & 3 & 3 & 3 & 3 & 3 \\
\hline
\end{tabular}

${ }^{*} P<0.05 ; * * P<0.01 ; * * * P<0.0005$ compared with "unexplained" gynaecomastia (Mann-Whitney). $P$-values in parenthesis were no longer significant after adjusting for age in a logistic regression model. 


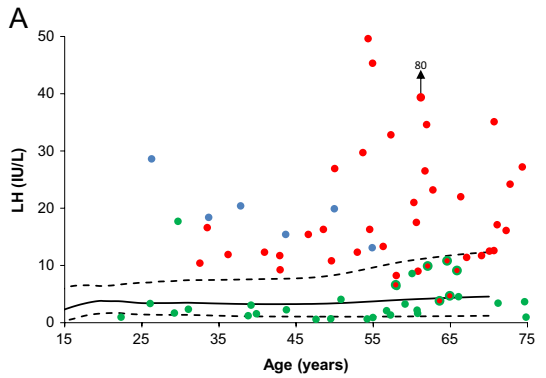

B
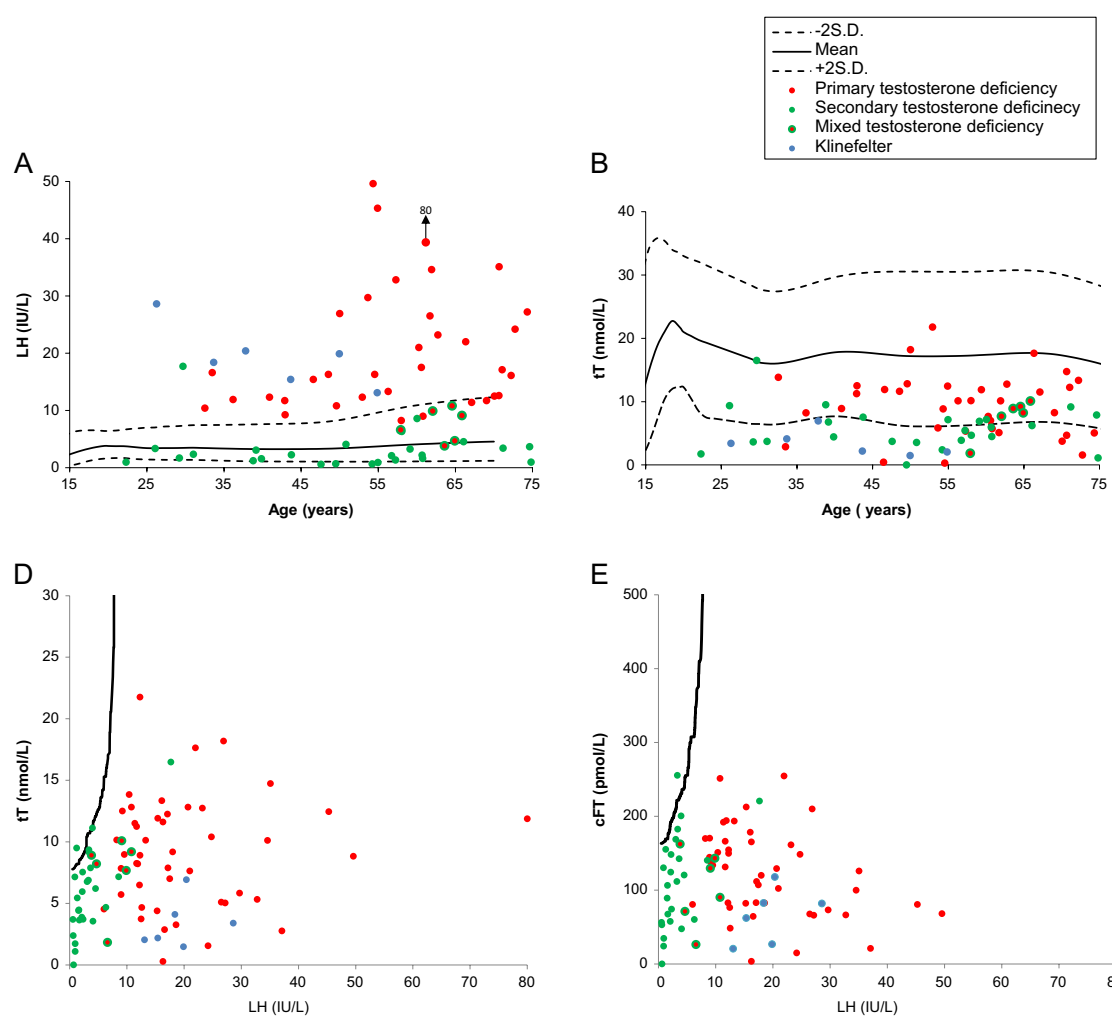

E

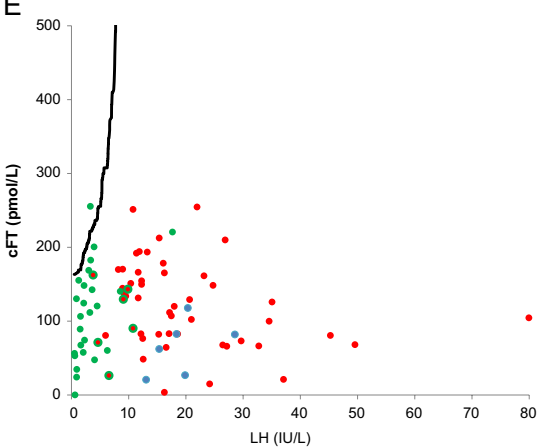

C

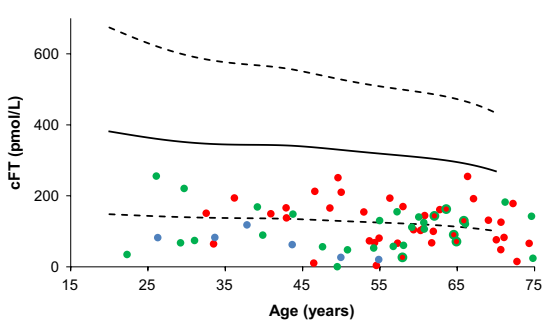

- Klinefelter

\section{Figure 2}

(A, B and C) Testosterone (tT), free testosterone (cFT) and LH according to age in men with primary (red), secondary (green) and mixed (red/green) testosterone deficiency and Klinefelter syndrome (blue) compared to mean and \pm 2 s.D. of a normal material of healthy Danish men. (D and E) Ratios of testosterone (tT) and free testosterone (cFT) according to LH in men with primary (red), secondary (green) and mixed (red/green) testosterone deficiency and Klinefelter syndrome (blue). $95 \%$ of healthy Danish adult men are on the left side of the black line.

for gynaecomastia. They had highly elevated SHBG, E2 and LH, whereas cFT and inhibin B were low. E2/tT and cFE2/cFT were elevated and tT/LH, cFT/LH and inhibin $\mathrm{B} / \mathrm{FSH}$ were lowered (all $P<0.01$ ). When controlling for age, the difference in $\mathrm{LH}, \mathrm{SHBG}$ and $\mathrm{cFE} 2 / \mathrm{cFT}$ remained significant.

One man was diagnosed with renal insufficiency (elevated creatinine and carbamide). His tT, cFT and SHBG were low, hence, altering the ratios of E2/tT (high), $\mathrm{tT} / \mathrm{LH}$ (low) and cFT/LH (low).

Eighteen men were diagnosed with endocrine disorders (hyperthyroidism ( $n=10$, having high (normal) testosterone, SHBG and elevated E2/tT and especially E2/cFT), hyperprolactinaemia ( $n=7$, having secondary testosterone deficiency) and Cushing's disease $(n=1$, having elevated androstendion and besides gynaecomastia also a Cushingoid appearance).

The palpation of the breast tissue of three men raised suspicion of unilateral breast cancer as their breast tissues were hard and irregular. Further evaluation including biopsy confirmed the suspicion in two of these men aged 77 and 69 years $(0.4 \%$ of men with no AAS). The hormonal testing of these men was normal. The oldest of the two men with breast cancer actually also had bilateral gynaecomastia, that had lasted for several years until a recent additional unilateral breast development made him seek his GP for this.

\section{More than one underlying cause}

Twelve percent of the men with adult onset of gynaecomastia had more than one underlying cause of breast development - predominantly with primary testosterone deficiency or medication as main treatable cause.

\section{Discussion}

In this prospective study, we report frequent findings of underlying pathologies in men evaluated because 
Table 4 Medication used by men categorized with medication as underlying cause of gynaecomastia $(n=85)$. 16 men had more than a single drug proposed to cause gynaecomastia. $50 \%$ of men using Simvastatin also used other medication able to cause gynaecomastia.

\begin{tabular}{|c|c|c|}
\hline Medicinal group & Drug & $n$ \\
\hline \multirow[t]{6}{*}{ Cardiovascular agents } & Spironolacton & 19 \\
\hline & Digoxin & 6 \\
\hline & Enalapril & 5 \\
\hline & Amlodipin & 4 \\
\hline & Verapamil & 2 \\
\hline & Unknown ACE inhibitor & 1 \\
\hline \multirow[t]{2}{*}{ 5-alpha reductase inhibitors } & Dutasterid & 4 \\
\hline & Finasterid & 4 \\
\hline \multirow[t]{5}{*}{ Opioids } & Morphine & 6 \\
\hline & Tramadol & 5 \\
\hline & Buprenorphin & 2 \\
\hline & Metadon & 3 \\
\hline & Oxycodon & 1 \\
\hline \multirow[t]{2}{*}{ Anti-psychotics } & Risperidon & 2 \\
\hline & Chlorprotixen & 2 \\
\hline \multirow[t]{3}{*}{ Anti-depressants } & Nortriptylin & 1 \\
\hline & Sertralin & 1 \\
\hline & Olansapin & 1 \\
\hline Neuroleptics & Unknown & 1 \\
\hline Anti-retroviral & Unknown & 3 \\
\hline \multirow[t]{3}{*}{ Statins } & Simvastatin & 10 \\
\hline & Atorvastatin & 5 \\
\hline & Rosuvastatin & 2 \\
\hline \multirow[t]{5}{*}{ Antacids } & Omeprazole & 2 \\
\hline & Pantoprazole & 2 \\
\hline & Lansoprazole & 1 \\
\hline & Esomeprazol & 1 \\
\hline & $\begin{array}{l}\text { Unknown proton pump } \\
\text { inhibitor }\end{array}$ & 1 \\
\hline \multirow[t]{4}{*}{ Immunosuppressant agents } & Methotrexate & 1 \\
\hline & Glukokorticoids & 1 \\
\hline & Ciclosporin & 1 \\
\hline & Prednisolone & 1 \\
\hline Natural remedy & 'Saw palmetto' & 1 \\
\hline
\end{tabular}

of gynaecomastia. Using a standardised and simple diagnostic procedure, we detected pathological findings in $43 \%$ of men with no prior misuse of steroids. These causes included testosterone deficiency, use of medication, hyperthyroidism, hyperprolactinaemia, Klinefelter syndrome and testicular tumours. This emphasises that adult onset gynaecomastia may be a clinical sign of an underlying disease in a significant proportion of men.

The men we diagnosed with an underlying reason for their gynaecomastia had no prior knowledge of these reasons. Although not reported here in detail, the patients generally had not primarily complained of any other symptoms (e.g. fatigue, affected memory, decreasing muscle strength etc. were only unmasked after a detailed questioning). In some men, potentially serious conditions such as testicular tumours, hyperthyroidism and hyperprolactinaemia were diagnosed because of a primary complaint of gynaecomastia. Other publications have also described gynaecomastia as the first symptom of underlying diseases $(22,23,24)$, but despite this, it is not always a common practice to refer men with gynaecomastia for an andrological examination before referring them to cosmetic surgery (25). Due to the large number of men with hitherto unknown testicular problems, it seems appropriate to suggest that men with gynaecomastia should undergo a thorough andrological examination, including examination of the testicles.

Our study has several strengths. It was based on a large consecutively referred group of patients, the hormone assessments were done in a single certified laboratory, and the standardised work-up was performed by doctors who were trained andrologists and certified in testicular ultrasound. All men were investigated because they sought medical care because of the gynaecomastia that in most men were recently developed. We did not systematically record whether the gynaecomastia was associated with tenderness, but the clinical impression is that it was the case in approximately 50\%. The largest limitation of this study lies in the risk of selection bias. Our clinic belongs to a tertiary centre, and although we have our local catchment area from which general practitioners (GPs) refer men for a primary diagnostic work-up, we do not have any information about how many men these GP's actually saw due to breast development and did not refer to us. However, the patients had not had any systematic biochemical screening performed prior to referral, and thus, selection bias because of biochemistry seems low - except for the fact that many GPs in our experience tend to measure prolactin prior to referring patients. Thus, men with increased prolactin levels might have been referred elsewhere primarily and may be underrepresented in our study. Similarly, men who were in antiandrogen or other androgen deprivation treatment, because of prostate cancer, were not referred for investigation. Another limitation is that we did not have access to investigate men who were referred directly by their GP to private clinics of plastic surgery or who sought cosmetic correction without consulting their GP first. This may be the case for many men who have had used anabolic steroids when their gynaecomastia developed, and these men are usually not offered investigation of an underlying cause. We classified gynaecomastia as caused by medication if gynaecomastia was a known side effect of the drug. Some drugs are associated with a high risk of development and other 
drugs a lower risk; we could not determine to which degree the drugs actually were the cause as we did not follow the men classified by gynaecomastia caused by medication after our initial screening to test if changes in medication changed the presence of gynaecomastia. Secondly, there are certainly groups of drugs that could not be replaced. Assuming that the drugs considered being causal in reality was unrelated to gynaecomastia, these men should be added to the group of men with unexplained gynaecomastia. Thus, the number of men in other groups would remain the same. The distinction between gynaecomastia and lipomastia can be difficult in very obese individuals - and as we did not routinely use ultrasound imaging to support the diagnosis, it is possible that men with breast enlargement due to fat tissue alone have been misdiagnosed as having gynaecomastia. It can be speculated that such men will tend to end up by being classified as 'unexplained'; however, the BMI of that group did not differ much from the other classification groups.

We did not perform follow-up on the men in this study as our main function was diagnostic. Only men diagnosed with testosterone deficiency were treated in our department. Men with other conditions were referred on to other departments for treatment.

Our results highlight the usefulness of a thorough patient history including information of time of onset of gynaecomastia. To which degree gynaecomastia in puberty needs a diagnostic work-up is controversial, but this study indicates that even if pubertal gynaecomastia persists, it is most often not because of underlying pathology. In adult men with gynaecomastia since puberty, an underlying illness is less likely and inquiring about substance abuse and examination of testis size may suffice. Extremely small testicles could indicate Klinefelter syndrome and should lead to a more detailed investigation. Men with adult onset of gynaecomastia concomitant with ASS do most likely not need a thorough work-up - the endocrine profile will be disturbed and may be difficult to interpret if the abuse is ongoing or recent. The association between AAS and the development of gynaecomastia is well known $(26,27,28,29)$ and men who reported using anabolic steroids at referral were not offered further investigation. This was also the case for men in anti-androgenic treatment due to prostate cancer as this is also known to cause gynaecomastia (30). The mechanism behind breast development in men with abuse of cannabis is thought to be the similarity in the chemical structure between E2 and cannabinol (the major active component in marihuana), rather than changes in hormone levels (10). However, the group of men with cannabis abuse in our study is too small to conclude on.

A thorough diagnostic work-up ought to be done only on those with adult onset gynaecomastia provided that they are not in androgen deprivation therapy or are abusing AAS. AAS abuse does not exclude other underlying pathology but renders analysis of hormones levels virtually impossible. Exclusion of a testicular tumour may be sufficient. In our study, almost $10 \%$ of the patients presented with more than one obvious explanation, with testicular insufficiency and use of medication the most common combination. Thus, identification of one obvious cause for gynaecomastia such as medication should not preclude a detailed investigation.

The men with testosterone deficiency had low levels of $\mathrm{tT}$, cFT or testosterone-LH levels outside the reference level in the bivariate plot indicating Leydig cell impairment. Their E2 levels were not increased as such; however, the E2/T balance tended to a shift toward oestrogen. These

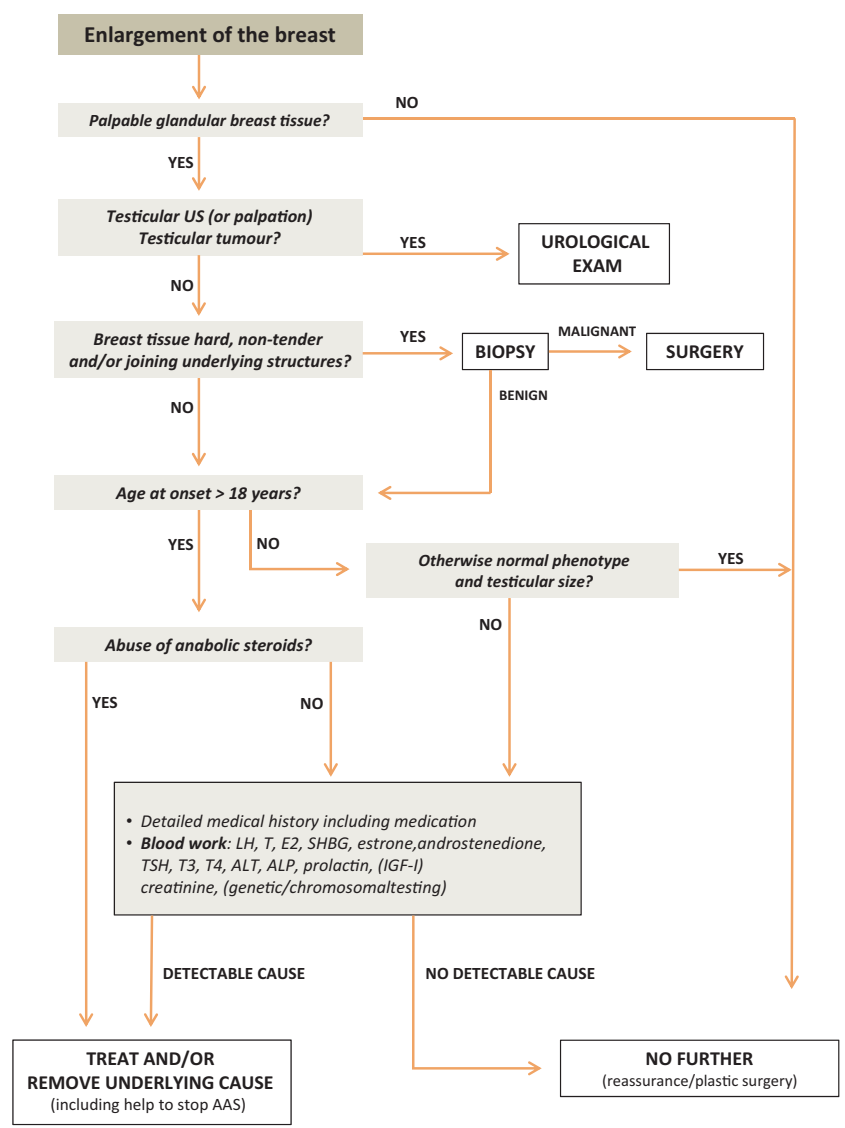

Figure 3

Flow chart displaying a comprehensible clinical and biochemical work-up of adult men presenting with breast development. 
findings support that the balance between androgens and estrogens is an important factor in the development of gynaecomastia, with estradiol promoting breast development and testosterone inhibiting the development of glandular tissue (1). Thus, even men with testosterone in the low-normal range may benefit from testosterone substitution.

In a large proportion of men, medications for comorbidities were the only factor identifiable as causing gynaecomastia. The classification of the medicine, in Table 4 as cause of gynaecomastia, is based on available knowledge $(31,32,33)$. For many drugs, the exact mechanisms for inducing gynaecomastia remain unknown $(9,34)$. Nevertheless, it is important to consider the choice of medication and the possibility to change the current treatment to avoid breast development. In cases where medication cannot be substituted, therapy of e.g. testosterone deficiency could be initiated.

We detected breast cancer in two men. We did, however, only see men referred under the diagnosis of 'gynaecomastia' as men referred under the diagnosis of 'breast cancer' are primarily seen by breast cancer surgeons. A recent study described a 10-fold higher risk of breast cancer in men who have had gynaecomastia (35). The mechanism is unknown, but it is speculated that the altered sex hormone balance, in favour of increased oestradiol/testosterone, could cause abnormal stimulation of the breast tissue (36). Alternatively, it might be due to the simple fact that the breast cancer was regarded as gynaecomastia before further examination (37).

In conclusion, we detected endocrinological diseases, including testosterone deficiency, thyrotoxicosis, Cushing's disease, hyperprolactinaemia and testicular cancer among our patients referred with gynaecomastia. More than one likely reason for gynaecomastia was also a frequent finding. Thus, identification of one obvious cause for gynaecomastia such as medication should not preclude a detailed investigation. This stresses the importance of a thorough examination to disclose any underlying pathology leading to the development of gynaecomastia in adulthood. Even in older men, where the usefulness has been questioned (38) and gynaecomastia has been suggested to be a normal physiological change (39), we often detected a treatable underlying cause. The age of men in whom we detected an underlying cause for gynaecomastia was substantially higher than those in whom the reason remained unexplained. Based on our experience, we propose that the examination procedure can be done in structured and simple setup as illustrated in Fig. 3.
Declaration of interest

The authors declare that there is no conflict of interest that could be perceived as prejudicing the impartiality of this study.

\section{Funding}

Support from the Research Fund of Rigshospitalet was given to M G M (grant no. 9595-33563), A J U (grant no. 9615.05.8.87) and N J (grant no. R42-A1326).

\section{References}

1 Braunstein GD. Gynecomastia. New England Journal of Medicine 1993 328 490-495. (doi:10.1056/NEJM199302183280708)

2 Braunstein GD. Clinical practice. Gynecomastia. New England Journal of Medicine 2007357 1229-1237. (doi:10.1056/NEJMcp070677)

3 Chan WB, Yeung VT, Chow CC, So WY \& Cockram CS. Gynaecomastia as a presenting feature of thyrotoxicosis. Postgraduate Medical Journal 199975 229-231. (doi:10.1136/ pgmj.75.882.229)

4 Ahmed M, Kanji A \& Begum T. Gynaecomastia: an unusual presenting symptom of bladder cancer. BMJ Case Reports 2015. (doi:10.1136/bcr2015-210649)

5 Kim I, Young RH \& Scully RE. Leydig cell tumors of the testis. A clinicopathological analysis of 40 cases and review of the literature. American Journal of Surgical Pathology 19859 177-192. (doi:10.1097/00000478-198503000-00002)

6 Russo J \& Russo IH. Development of the human breast. Maturitas 200449 2-15. (doi:10.1016/j.maturitas.2004.04.011)

7 Mieritz MG, Rakêt LL, Hagen CP, Nielsen JE, Talman M-LM, Petersen JH, Sommer SH, Main KM, Jørgensen N \& Juul A. A longitudinal study of growth, sex steroids, and IGF-1 in boys with physiological gynecomastia. Journal of Clinical Endocrinology and Metabolism 2015 100 3752-3759. (doi:10.1210/jc.2015-2836)

8 Hellmann P, Christiansen P, Johannsen TH, Main KM, Duno M \& Juul A. Male patients with partial androgen insensitivity syndrome: a longitudinal follow-up of growth, reproductive hormones and the development of gynaecomastia. Archives of Disease in Childhood 2012 97 403-409. (doi:10.1136/archdischild-2011-300584)

9 Thompson DF \& Carter JR. Drug-induced gynecomastia. Pharmacotherapy 199313 37-45.

10 Harmon J \& Aliapoulios MA. Gynecomastia in marihuana users. New England Journal of Medicine 1972287 936. (doi:10.1056/ nejm197211022871824)

11 Angell PJ, Chester N, Sculthorpe N, Whyte G, George K \& Somauroo J. Performance enhancing drug abuse and cardiovascular risk in athletes: implications for the clinician. British Journal of Sports Medicine 201246 (Supplement 1) i78-i84. (doi:10.1136/ bjsports-2012-091186)

12 Hatton CK, Green GA \& Ambrose PJ. Performance-enhancing drugs: understanding the risks. Physical Medicine and Rehabilitation Clinics of North America 201425 897-913. (doi:10.1016/j. pmr.2014.06.013)

13 Bowers SP, Pearlman NW, McIntyre RC, Finlayson CA \& Huerd S. Cost-effective management of gynecomastia. American Journal of Surgery 1998176 638-641. (doi:10.1016/S0002-9610(98)00281-5)

14 Lenz S, Skakkebaek NE \& Hertel NT. Abnormal ultrasonic pattern in contralateral testes in patients with unilateral testicular cancer. World Journal of Urology 199614 (Supplement 1) S55-S58.

15 Søeborg T, Frederiksen H, Fruekilde P, Johannsen TH, Juul A \& Andersson AM. Serum concentrations of DHEA, DHEAS, $17 \alpha$-hydroxyprogesterone, $\Delta 4$-androstenedione and testosterone in children determined by TurboFlow-LC-MS/MS. Clinica Chimica Acta 2013419 95-101. (doi:10.1016/j.cca.2013.01.019) 
16 Mazer NA. A novel spreadsheet method for calculating the free serum concentrations of testosterone, dihydrotestosterone, estradiol, estrone and cortisol: with illustrative examples from male and female populations. Steroids $2009 \mathbf{7 4} 512-519$. (doi:10.1016/j. steroids.2009.01.008)

17 Andersen AG. High frequency of sub-optimal semen quality in an unselected population of young men. Human Reproduction $2000 \mathbf{1 5}$ 366-372. (doi:10.1093/humrep/15.2.366)

18 Jensen TK, Andersson AM, Hjollund NH, Scheike T, Kolstad H, Giwercman A, Henriksen TB, Ernst E, Bonde JP, Olsen J et al. Inhibin $B$ as a serum marker of spermatogenesis: correlation to differences in sperm concentration and follicle-stimulating hormone levels. A study of 349 Danish men. Journal of Clinical Endocrinology and Metabolism 199782 4059-4063. (doi:10.1210/jc.82.12.4059)

19 Gyllenborg J, Rasmussen SL, Borch-Johnsen K, Heitmann BL, Skakkeb[aelig ]k NE \& Juul A. Cardiovascular risk factors in men: the role of gonadal steroids and sex hormone-binding globulin. Metabolism 200150 882-888. (doi:10.1053/meta.2001.24916)

20 Aksglaede L, Skakkebaek NE, Almstrup K, Juul A, Aksglaede L \& Skakkebaek NE. Clinical and biological parameters in 166 boys, adolescents and adults with nonmosaic Klinefelter syndrome: a Copenhagen experience. Acta Paediatrica 2011100 793-806. (doi:10.1111/j.1651-2227.2011.02246.x)

21 Aksglaede L, Petersen JH, Main KM, Skakkebaek NE \& Juul A. High normal testosterone levels in infants with non-mosaic Klinefelter's syndrome. European Journal of Endocrinology 2007157 345-350. (doi:10.1530/EJE-07-0310)

22 Kolitsas N, Tsambalas S, Dimitriadis F, Baltogiannis D, Vlachopoulou E, Vappa S, Giannakis D, Tsounapi P, Takenaka A \& Sofikitis N. Gynecomastia as a first clinical sign of nonseminomatous germ cell tumor. Urologia Internationalis 201187 248-250. (doi:10.1159/000328387)

23 Kayemba-Kay's S, Fromont-Hankard G, Lettelier G, Gabriel S \& Levard G. Leydig cell tumour revealed by bilateral gynecomastia in a 15-year old adolescent: a patient report. Journal of Pediatric Endocrinology and Metabolism 201023 1195-1199. (doi:10.1515/ jpem.2010.188)

24 Kaptanis S, Parvanta L \& Beltran L. Testicular seminoma presenting as unilateral gynecomastia. Breast Journal 201420 424-426. (doi:10.1111/tbj.12287)

25 Al-Allak A, Govindarajulu S, Shere M, Ibrahim N, Sahu AK \& Cawthorn SJ. Gynaecomastia: a decade of experience. Surgeon 20119 255-258. (doi:10.1016/j.surge.2010.10.004)
26 Nieschlag E \& Vorona E. Mechanisms in endocrinology: medical consequences of doping with anabolic androgenic steroids: effects on reproductive functions. European Journal of Endocrinology 2015173 R47-R58. (doi:10.1530/EJE-15-0080)

27 Sjöqvist F, Garle M \& Rane A. Use of doping agents, particularly anabolic steroids, in sports and society. Lancet 2008371 1872-1882. (doi:10.1016/s0140-6736(08)60801-6)

28 Hall RCW \& Hall RCW. Abuse of supraphysiologic doses of anabolic steroids. Southern Medical Journal 200598 550-555. (doi:10.1097/01. SMJ.0000157531.04472.B2)

29 Anderson SJ. Adolescents and anabolic steroids: a subject review. Pediatrics 199799 904-908. (doi:10.1542/peds.99.6.904)

30 Thompson CA. Andropause: symptom management for prostate cancer patients treated with hormonal ablation. Oncologist 20038 474-487. (doi:10.1634/theoncologist.8-5-474)

31 Eckman A \& Dobs A. Drug-induced gynecomastia. Expert Opinion on Drug Safety 20087 691-702. (doi:10.1517/14740330802442382)

32 Deepinder F \& Braunstein GD. Drug-induced gynecomastia: an evidence-based review. Expert Opinion on Drug Safety 201211 779-795. (doi:10.1517/14740338.2012.712109)

33 Bowman JD, Kim H \& Bustamante JJ. Drug-induced gynecomastia. Pharmacotherapy 201232 1123-1140. (doi:10.1002/phar.1138)

34 García Rodríguez LA \& Jick H. Risk of gynaecomastia associated with cimetidine, omeprazole, and other antiulcer drugs. BMJ 1994308 503-506. (doi:10.1136/bmj.308.6927.503)

35 Brinton LA, Cook MB, McCormack V, Johnson KC, Olsson H, Casagrande JT, Cooke R, Falk RT, Gapstur SM, Gaudet MM et al. Anthropometric and hormonal risk factors for male breast cancer: male breast cancer pooling project results. Journal of the National Cancer Institute 2014106 djt465. (doi:10.1093/jnci/djt465)

36 Weiss JR, Moysich KB \& Swede H. Epidemiology of male breast cancer. Cancer Epidemiology, Biomarkers and Prevention 200514 $20-26$.

37 de Bree E, Tsagkatakis T, Kafousi M \& Tsiftsis DD. Breast enlargement in young men not always gynaecomastia: breast cancer in a 22 -yearold man. ANZ Journal of Surgery 200575 914-916. (doi:10.1111/ j.1445-2197.2005.03572.x)

38 Niewoehner CB \& Schorer AE. Gynaecomastia and breast cancer in men. BMJ 2008336 709-713. (doi:10.1136/bmj.39511. 493391.BE)

39 Nuttall FQ. Gynecomastia as a physical finding in normal men. Journal of Clinical Endocrinology and Metabolism 201448 338-340. (doi:10.1210/jcem-48-2-338)

Received 1 August 2016

Revised version received 28 December 2016

Accepted 7 February 2017 